\title{
Correction to: Iridium Catalysts for Organic Reactions
}

\author{
Luis A. Oro and Carmen Claver
}

\section{Correction to:}

\section{A. Oro, C. Claver (eds.), Iridium Catalysts for Organic Reactions, Topics in Organometallic Chemistry 69, https://doi.org/10.1007/978-3-030-69083-0}

This book was inadvertently published without updating the following corrections:

p. 229 , the word "provably" changed to "probably"

p. 231 , the letter "a" added before " $6 / 1$ "

p. 232 , deleted the words "at 11 "

p. 239, the word "pathways" changed to "tools"

p. 245, the word "catalyst" changed to "catalysts"

p. 248 , the equation $[\operatorname{IrH}(\kappa[9]$-hqca $)(\mathrm{COE})]$ changed to $\left[\operatorname{IrH}\left(\kappa^{3}-O, N, O^{\prime}\right.\right.$-hqca (COE)]

p. 255, deleted "(Scheme 28)" after the word "intermediate"

p. 255 , the word "Scheme 28 " added after the word coupling

p. 261, the size of Scheme 37 is reduced

p. 320 , in reference 28 , the name "Gunaseker" is changed to "Gunasekar"

p. 321 , in reference 48 , the year 2001 is changed to 2011

p. 322, in reference 75 , the word "Sustain" is changed to "Sustainable"

p. 324 , in reference 103 , the word "WA" is changed to "WE"

These corrections had been updated.

\footnotetext{
The updated online version of these chapters can be found at https://doi.org/10.1007/3418_2020_55 https://doi.org/10.1007/3418_2020_52
} 